Fukushima J. Med. Sci.,

Vol. 58, No. 2, 2012

[Original Article]

\title{
A REDUCTION OF CORONARY FLOW RESERVE IS ASSOCIATED WITH CHRONIC KIDNEY DISEASE AND LONG-TERM CARDIO-CEREBROVASCULAR EVENTS IN PATIENTS WITH NON-OBSTRUCTIVE CORONARY ARTERY DISEASE AND VASOSPASM
}

\author{
NOBUO SAKAMOTO, SHOJI IWAYA, TAKASHI OWADA, YUICHI NAKAMURA, \\ HIROYUKI YAMAUCHI, YASUTO HOSHINO, HIROYUKI MIZUKAMI, KOICHI SUGIMOTO, \\ TAKAYOSHI YAMAKI, HIROYUKI KUNII, KAZUHIKO NAKAZATO, HITOSHI SUZUKI, \\ SHU-ICHI SAITOH and YASUCHIKA TAKEISHI
}

Department of Cardiology and Hematology, Fukushima Medical University, Fukushima, Japan

(Received March 5, 2012, accepted June 13, 2012)

\begin{abstract}
Background : Coronary flow reserve (CFR) provides essential information about the coronary microvasculature. Chronic kidney disease (CKD) is a risk factor for cardio-cerebrovascular diseases. We hypothesized that low CFR is associated with CKD and long-term cardio-cerebrovascular events in the patients without obstructive coronary artery diseases and vasospasm.

Method and Results : In this study, 73 patients suspected with coronary artery disease but had no epicardial coronary stenosis and vasospasm were enrolled. There were $13 \mathrm{CKD}$ patients and CFR was measured using the Doppler flow wire methods in the left anterior descending artery. CFR was significantly lower in CKD group than non-CKD group $(3.13 \pm 0.6$ vs. $4.00 \pm 1.1, P=$ 0.007). From multivariate logistic regression analysis, the independent factor associated with the presence of CKD was only CFR (odds ratio 3.85, 95\% confidence interval 1.27-11.70, $P=0.017$ ). In the patients with low CFR $(\leq 2.8)$, cardio-cerebrovascular events were more common than those with normal CFR (CFR >2.8). Besides, in the patients who had both low CFR and CKD, longterm cardio-cerebrovascular events were more likely to occur than those with normal CFR or nonCKD.

Conclusions : Our data suggest that low CFR is associated with CKD and cardio-cerebrovascular events in the patients without coronary stenosis and vasospasm.
\end{abstract}

Key words : coronary flow reserve (CFR), doppler flow wire, coronary microcirculation, chronic kidney disease (CKD), cardio-cerebrovascular event

\section{INTRODUCTION}

Approximately $10 \%$ to $30 \%$ of patients who had angina-like chest pain referred for cardiac catheterization are found to have either normal coronary arteries or only a minimal degree of atherosclero$\operatorname{sis}^{1-3)}$. Some of those patients are found to have other forms of heart disease such as hypertrophic cardiomyopathy and coronary artery spasm. Coronary flow reserve (CFR) provides essential information about the coronary microvascular bed in the absence of narrowing of epicardial coronary arteries. Impairment of CFR may result from vasomotor, metabolic or structural abnormalities in

坂本信雄, 岩谷章司, 大和田卓史, 中村裕一, 山内宏之, 星野寧人, 水上浩行, 杉本浩一, 八巻尚洋, 國井 浩行, 中里和彦, 鈴木 均, 斎藤修一, 竹石恭知

Corresponding author : Nobuo Sakamoto, MD E-mail address : sakanobu@fmu.ac.jp

https://www.jstage.jst.go.jp/browse/fms http://www.fmu.ac.jp/home/lib/F-igaku/ 
the coronary microcirculation and may precede coronary atherosclerosis ${ }^{4}$.

Not only severe renal disease, mild renal disease is accompanied by increased cardiovascular risk and mortality ${ }^{5-8}$. Besides, it has been also reported that the renal dysfunction increased the risk of cerebral infarction ${ }^{9)}$. Glomerular filtration rate (GFR) may in part reflect and rely on the integrity of the renal microvascular bed. Although it has been reported that microvascular dysfunction is a systemic disorder that might cause parallel deleterious alterations in both the coronary and the renal microvasculature at early stages ${ }^{10)}$, the pathophysiological mechanisms between CFR and renal dysfunction remain to be fully elucidated. Besides, although several studies reported that reduction in CFR may be associated with increased cardiovascular mortality in patients with normal coronary arteries $^{11-13)}$, the association with CFR and cerebrovascular event, especially in the presence of CKD, was unclear.

The aim of the present study was to assess the relationships between CFR and chronic kidney disease (CKD), and the long-term cardio-cerebrovascular event of CFR response in patients without epicardial coronary stenosis and vasospasm.

\section{METHODS}

Study protocol was approved by the institutional review board. Informed consent was obtained from all patients in this study.

Study population: The patients who suspected coronary artery disease but had no obstructive coronary artery disease and vasospasm estimated by control coronary arteriography (CAG) and coronary spasm provocation test, were enrolled in the present study. After exclusion of patients with moderate to severe valvular disease, left ventricular ejection fraction (LVEF) of less than $50 \%$ by echocardiography, previous myocardial infarction, cerebral infarction and hypertrophic or dilated cardiomyopathy, 73 patients were examined for the assessment of CFR from 1993 to 2008 (mean age, $62.7 \pm 9.3$ years). To allow the assessment of coronary physiology at baseline, calcium channel-blocking agents, long-acting nitrates and $\beta$-blocker were withheld at least 48 hours before CAG and CFR measurement.

We also assessed coronary risk factors, including a history of smoking, hypertension, dyslipidemia and diabetes mellitus. Hypertension was defined as systolic blood pressure $\geq 140 \mathrm{mmHg}$ or diastolic blood pressure $\geq 90 \mathrm{mmHg}$, and/or under antihypertensive treatment. Dyslipidemia was defined as total cholesterol $\geq 220 \mathrm{mg} / \mathrm{dl}$, fasting triglycerides $\geq 150 \mathrm{mg} / \mathrm{dl}$ or under lipid-lowering treatment. Diabetes mellitus was defined as fasting plasma glucose $\geq 126 \mathrm{mg} / \mathrm{dl}$, postprandial blood glucose $\geq 200 \mathrm{mg} / \mathrm{dl}$, and/or under glucose-lowering treatment.

Assessment of renal function : We calculated the estimated GFR (eGFR) from age and serum creatinine (Scr) using the Japanese GFR estimation equation proposed by the Japanese Society of Nephlogy as follows: $\mathrm{eGFR}=194 \times \mathrm{Scr}^{-1.094} \times$ $\operatorname{age}^{-0.287}$ (if female, $\left.\times 0.739\right)^{14}$. The presence or absence of CKD was defined by using the cut-off of $60 \mathrm{ml} / \mathrm{min} / 1.73 \mathrm{~m}^{2}$ as the lower limit of eGFR for normal renal function ${ }^{15)}$. The patients were subsequently divided into two groups, CKD group and non-CKD group, according to their renal functions as assessed by eGFR just in prior to CAG.

Study protocol and measurement of CFR : Diagnostic CAG was performed using $5 \mathrm{Fr}$. or $6 \mathrm{Fr}$. Judkins catheter with a standard femoral percutaneous approach. Heparin sodium (3,000 units) was administered intravenously at the beginning of the procedure. If there was no significant epicardial coronary stenosis by control CAG and coronary vasospasm was not evoked by the two to three doses of intracoronary administration of acetylcholine $(25,50$ and $100 \mu \mathrm{g}$ for the left coronary artery ; 25 and $50 \mu \mathrm{g}$ for the right coronary artery, for 30 seconds each), CFR was then assessed. The coronary spasm provocation test was considered positive when an ischemic electrocardiogram changes and/or chest pain with coronary constriction was induced by intracoronary administration of acetylcholine, based on the 2008 Guidelines of the Japanese Circulation Society ${ }^{16)}$. For the assessment of CFR, first, a 0.014 inch Doppler guide wire (Volcano, Rancho Cordova, CA, USA) was placed in the proximal portion of the left anterior coronary (LAD) artery to measure the average peak flow velocity [APV ( $\mathrm{cm} / \mathrm{second})]$ of the coronary artery. Second, by intracoronary nitroglycerin (2.5 mg bolus) administration, the epicardial portion of the left coronary artery was kept maximally dilated, following which papaverine (12 $\mathrm{mg}$ for 10 seconds) was administered into the left coronary artery through the same guiding catheter. Thus, the change in APV in response to intracoronary papaverine was considered as CFR to reflect the coronary microvascular function. We performed this protocol as described previously ${ }^{17)}$. 
Catamnestic follow-up: In May 2009, the patient's information was obtained by regular contacts with family doctors, and by telephone contacts with patients or patient families. The patients were prospectively followed-up to register cardiovascular events for on average follow-up period of $8.4 \pm 4.3$ years.

Statistical analysis : Results are presented as mean \pm standard deviation (SD) values for continuous variables and as the percentage of total patients for categorical variables. Unpaired Student $t$ test and Fisher's exact probability test were used for comparisons of continuous and categorical variables between 2 groups, respectively. If data were not distributed normally, the Mann-Whitney $U$ test was used. Correlation between CFR and eGFR was studied with the Pearson's correlation test. Logistic regression analysis was employed to calculate odds ratio (OR) and their 95\% confidence intervals (CI). Event-free survival was examined by Kaplan-Meier method and analyzed by a log-rank test. A value of $P<0.05$ was considered significant. All analyses were performed using StatView version 5 for windows (SAS Institute Inc., Cary, NC, USA).

\section{RESULTS}

Clinical characteristics of study subjects : All patients included in this study had no epicardial coronary artery stenosis and vasospasm, and they were divided into two groups according to their renal function as assessed by eGFR. There were 13 patients in CKD group and 60 patients in nonCKD group in this study. The main clinical baseline characteristics data grouped by eGFR are pre- sented in Table 1. Mean eGFR was $49.5 \pm 11.2$ $\mathrm{ml} / \mathrm{min} / 1.73 \mathrm{~m}^{2}$ in CKD group and $78.7 \pm 14.0 \mathrm{ml} /$ $\mathrm{min} / 1.73 \mathrm{~m}^{2}$ in non-CKD group. CFR was significantly lower in CKD group than non-CKD group (3.13 \pm 0.6 vs. $4.00 \pm 1.1, P=0.007)$. Although the patients in CKD group were more likely to be older than those in non-CKD group, there were no significant differences in gender between the two groups. Table 1 also shows no significant difference between the two groups with respect to the prevalence of cardio-cerebrovascular and/or renal risk factors (i.e. hypertension, dyslipidemia, diabetes mellitus and smoking). Besides, LVEF assessed by echocardiography was similar for the both groups.

Relationship between CFR value and eGFR : Patients with CKD group had significantly lower CFR than patients with non-CKD group (Table 1 ), and CFR was correlated with eGFR $(R=0.48$, $P<0.0001)$ as shown in Figure 1. Univariate logistic regression analysis revealed that the presence of CKD was significantly associated with CFR and age. Multivariate logistic regression analysis revealed that independent factor associated with the presence of CKD was only CFR (Table 2, OR 3.85, 95\% CI 1.27-11.70, $P=0.017$ ).

Prognostic value of CFR: There were total of 10 cardio-cerebrovascular events during followup periods ( 2 of cardiac sudden death, 5 of acute coronary syndrome and 3 of cerebral infarction). The best cut-off value of CFR to predict cardio-cerebrovascular events was 2.8 from receiver operating curve (ROC), and the value of CFR $\leq 2.8$ had $40 \%$ sensitivity and $87.5 \%$ specificity to detect patients with these events (area under ROC $=0.564$ ). There were 12 low CFR $(\leq 2.8)$ patients in this study and

Table 1. Characteristics of patients

\begin{tabular}{llccc}
\hline & & CKD & non-CKD \\
$(n=60)$ & $P$ value \\
\hline Age & $($ year $)$ & $68.3 \pm 6.9$ & $61.5 \pm 9.3$ & 0.015 \\
Male & $(n, \%)$ & $5(38.5)$ & $32(53.3)$ & n.s. \\
eGFR & $\mathrm{ml} / \mathrm{min} / 1.73 \mathrm{~m}^{2}$ & $49.5 \pm 11.2$ & $78.7 \pm 14.0$ & - \\
CFR & & $3.13 \pm 0.6$ & $4.00 \pm 1.1$ & 0.007 \\
LVEF & $(\%)$ & $63.9 \pm 9.4$ & $63.0 \pm 8.3$ & n.s. \\
Hypertension & $(n, \%)$ & $8(61.5)$ & $25(41.7)$ & n.s. \\
Dyslipidemia & $(n, \%)$ & $3(23.1)$ & $14(23.3)$ & n.s. \\
Diabetes mellitus & $(n, \%)$ & $2(15.4)$ & $4(6.7)$ & n.s. \\
Smoking & $(n, \%)$ & $2(15.4)$ & $9(15.0)$ & n.s. \\
\hline
\end{tabular}

CKD, chronic kidney disease; eGFR, estimated glomerular filtration rate; CFR, coronary flow reserve ; LVEF, left ventricular ejection fraction, n.s. ; not significant. 
Table 3 shows logistic regression analysis for low CFR. Univariate logistic regression analysis revealed that the presence of low CFR was significantly associated with age, CKD and the presence of

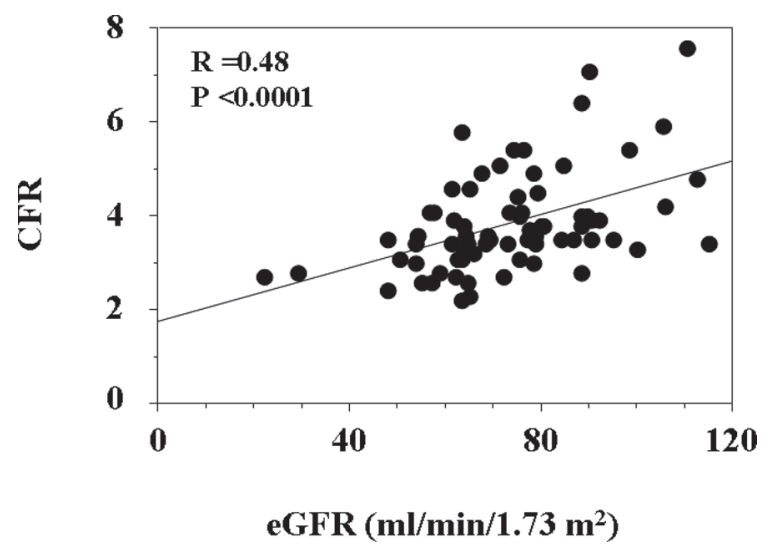

Fig. 1. The correlation between CFR value and eGFR. CFR was positively correlated with eGFR.

CFR, coronary flow reserve ; eGFR, estimated glomerular filtration rate. diabetes mellitus. Multivariate logistic regression analysis revealed that independent factors associated with low CFR were the presence of CKD and diabetes mellitus. Figure 2 shows Kaplan-Meier event-free curves for cardio-cerebrovascular events in low CFR patients and normal CFR patients. Normal CFR patients had better outcome than low CFR patients ( $P=0.033$ by log-rank test).

Prognostic value of CKD patients: There were 4 patients in CKD group and 6 patients in nonCKD group with cardio-cerebrovascular events. The event rate was significantly higher in CKD group than non-CKD group (30.8\% vs. $10.0 \%, P=$ 0.048). Kaplan-Meier event-free curves for cardio-cerebrovascular events in CKD and non-CKD groups are shown in Figure 3. Patients with nonCKD group had better outcome compared to those with CKD group $(P=0.0008$ by log-rank test). Table 4 shows comparisons of clinical characteristics between the patients with or without cardio-cerebrovascular events in CKD group. There were no statistically significant differences in age,

Table 2. Univariate and multivariate logistic regression analyses to predict the presence of CKD

\begin{tabular}{|c|c|c|c|c|}
\hline & Univariate & analysis & Multivariate & analysis \\
\hline & OR $(95 \%$ CI) & $P$ value & OR $(95 \% \mathrm{CI})$ & $P$ value \\
\hline Age (y) & $1.11(1.02-1.22)$ & 0.022 & $0.91(0.82-1.00)$ & 0.054 \\
\hline Sex (female) & $1.83(0.54-6.24)$ & 0.335 & & \\
\hline CFR & $4.41(1.46-13.33)$ & 0.026 & $3.85(1.27-11.70)$ & 0.017 \\
\hline LVEF & $0.99(0.92-1.06)$ & 0.727 & & \\
\hline Hypertension & $2.24(0.66-7.66)$ & 0.199 & & \\
\hline Dyslipidemia & $0.99(0.24-4.09)$ & 0.984 & & \\
\hline Diabetes mellitus & $2.55(0.41-15.66)$ & 0.313 & & \\
\hline Smoking & $1.03(0.20-5.45)$ & 0.972 & & \\
\hline
\end{tabular}

OR, odds ratio ; CI, confidence interval.

Table 3. Univariate and multivariate logistic regression analyses to predict low CFR $(\leq 2.8)$

\begin{tabular}{|c|c|c|c|c|}
\hline & Univariate & analysis & Multivariate & analysis \\
\hline & OR $(95 \% \mathrm{CI})$ & $P$ value & OR $(95 \% \mathrm{CI})$ & $P$ value \\
\hline Age (y) & $1.11(1.01-1.21)$ & 0.035 & $1.04(0.94-1.15)$ & 0.412 \\
\hline Sex (female) & $1.55(0.44-5.41)$ & 0.496 & & \\
\hline CKD & $7.71(1.94-30.62)$ & 0.004 & $6.68(1.36-32.94)$ & 0.020 \\
\hline LVEF & $1.00(0.93-1.08)$ & 0.986 & & \\
\hline Hypertension & $1.26(0.37-4.35)$ & 0.715 & & \\
\hline Dyslipidemia & $0.26(0.03-2.14)$ & 0.209 & & \\
\hline Diabetes mellitus & $14.75(2.32-93.92)$ & 0.004 & $11.95(1.44-98.98)$ & 0.021 \\
\hline Smoking & $1.16(0.22-6.17)$ & 0.866 & & \\
\hline
\end{tabular}


gender, eGFR, LVEF and prevalence of cardio-cerebrovascular and/or renal risk factors between the patients with and without events in CKD group. However, CFR was lower in the patients with events than those without events in CKD group ( $2.60 \pm 0.2$ vs. $3.37 \pm 0.5, P=0.016)$.

Prognostic value of both low CFR and CKD patients : Kaplan-Meier event-free curves for cardio-cerebrovascular events in the patients with both of low CFR and CKD are shown in Figure 4. In this study, there were 6 patients who had both low CFR and CKD. Among these, 4 patients had cardio-cerebrovascular events. The data showed that the patients with both of low CFR and CKD had worse outcome $(P<0.0001$ by log-rank test).

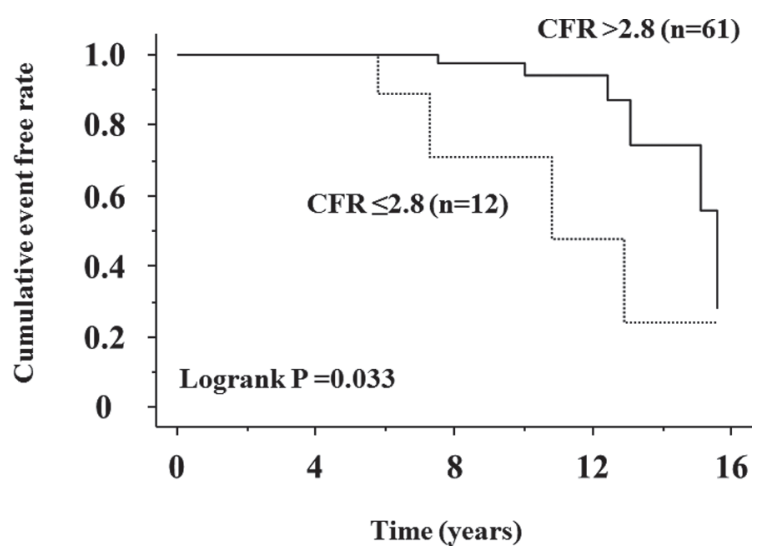

Fig. 2. Kaplan-Meier event-free curves (considering cardio-cerebrovascular events as an end point) in patients stratified according to low $(\leq 2.8)$ or normal $(>2.8)$ CFR at Doppler flow wire method. There were total of 10 cardio-cerebrovascular events during follow-up periods in this study. Event-free rate with a CFR $>2.8$ was significantly different from that with a CFR $\leq 2.8(P=0.033)$.

\section{DISCUSSION}

CFR is an integrating measure of endothelial function when there were no epicardial coronary stenoses $^{18,19)}$. Renal functional impairment was also associated with markers of endothelial dysfunc$\operatorname{tion}^{20)}$, and renal dysfunction was a short-term and long-term independent predictor of mortality ${ }^{21-23)}$. There were a few studies to compare coronary microvascular function with renal function. Chade et al. showed that reduced renal function is associated with attenuated coronary vasodilator capacity in patients without obstructive coronary artery disease ${ }^{10)}$. However, they found that differences in age, sex and prevalence of hypertension were largely responsible for the observed differences in CFR. Koivuviita et al. demonstrated that there was

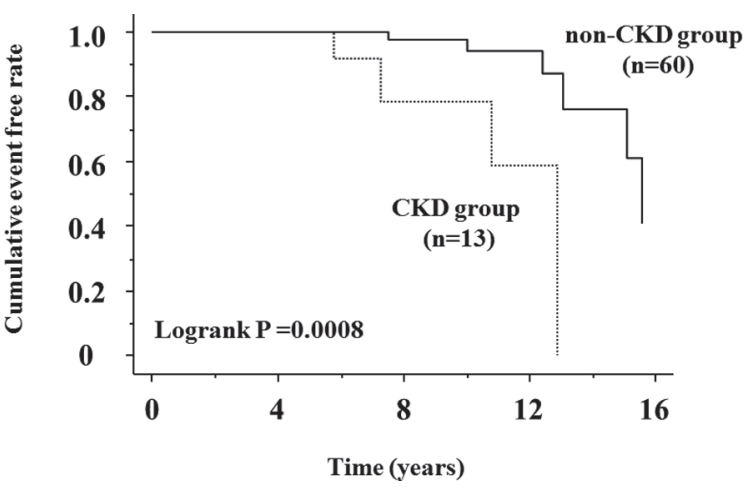

Fig. 3. Kaplan-Meier event-free curves (considering cardio-cerebrovascular events as an end point) in patients stratified according to CKD or non-CKD assessed by eGFR. Event-free rate with a CKD was significantly different from that with a nonCKD $(P=0.0008)$.

CKD, chronic kidney disease.

Table 4. Clinical characteristics between the patients with cardio-cerebrovascular events and those without events in CKD group

\begin{tabular}{llccc}
\hline & & $\begin{array}{c}\text { Event } \\
(n=4)\end{array}$ & $\begin{array}{c}\text { Event-free } \\
(n=9)\end{array}$ & $P$ value \\
\hline Age & $($ year $)$ & $67.3 \pm 3.4$ & $68.8 \pm 8.1$ & n.s. \\
Male & $(\mathrm{n}, \%)$ & $2(50.0)$ & $3(33.3)$ & n.s. \\
eGFR & $\mathrm{ml} / \mathrm{min} / 1.73 \mathrm{~m}^{2}$ & $54.7 \pm 4.7$ & $47.2 \pm 12.7$ & n.s. \\
CFR & & $2.60 \pm 0.2$ & $3.37 \pm 0.5$ & 0.016 \\
LVEF & $(\%)$ & $65.5 \pm 12.3$ & $63.2 \pm 8.6$ & n.s. \\
Hypertension & $(\mathrm{n}, \%)$ & $2(50.0)$ & $6(66.7)$ & n.s. \\
Dyslipidemia & $(\mathrm{n}, \%)$ & $0(0)$ & $3(33.3)$ & n.s. \\
Diabetes mellitus & $(\mathrm{n}, \%)$ & $1(25.0)$ & $1(11.1)$ & n.s. \\
Smoking & $(\mathrm{n}, \%)$ & $1(25.0)$ & $1(11.1)$ & n.s. \\
\hline
\end{tabular}




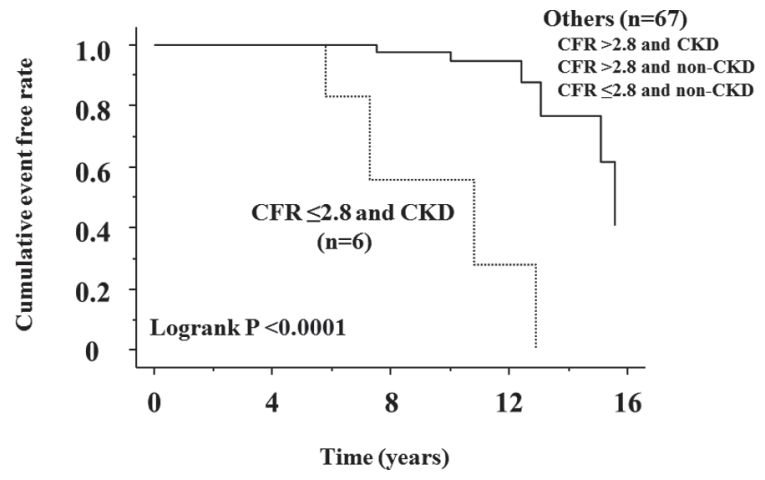

Fig. 4. Kaplan-Meier event-free curves (considering cardio-cerebrovascular events as an end point) in patients stratified according to both of low CFR and CKD, or the others. In this study, there were 6 patients with both of low CFR and CKD, and among these patients, there were 4 cardio-cerebrovascular events. Eventfree rate with both of low CFR and CKD was significantly different from that with normal CFR or non-CKD $(P<0.0001)$.

a trend toward low CFR with more significant CKD, but they did not find a significant association between $\mathrm{CFR}$ and $\mathrm{CKD}^{24)}$. On the other hand, Bezante $e t a l$. showed even after adjustment for age and gender, the presence of CKD entailed a sevenfold higher of having impaired $\mathrm{CFR}^{25}$, and Charytan et al. also examined low CFR may accelerate in mild to moderate $\mathrm{CKD}^{26)}$. In our study, although patients with CKD group were older, there were no significant differences in gender and the prevalence of hypertension between CKD and non-CKD groups. The value of CFR was significantly lower in CKD group than non-CKD group. Besides, CFR correlated with eGFR and multivariate logistic regression analysis revealed that independent factor associated with the presence of CKD was only CFR. These results suggest that CFR is associated with CKD in the patients without obstructive coronary artery disease and vasospasm. In addition, although it is recently reported that low GFR is associated with vasospastic angina ${ }^{27}$, all patients in this study were ruled out the possibility of vasospastic angina.

A reduction in CFR may play a role in the development of myocardial ischemia ${ }^{11-13)}$ and may be associated with increased cardiovascular mortality in patients with normal coronary arteries ${ }^{28)}$. CKD is strongly associated with increased risk of cardiovascular disease ${ }^{15,29,30)}$. Koren-Morag et al. described that about $1 / 5$ of patients with coronary heart disease had chronic renal dysfunction ${ }^{31}$. In addition,
Hao $Z$ et al. reported that more than $1 / 4$ of patients with acute cerebral infarction presented with renal dysfunction $^{32)}$. They also reported that reduced eGFR was independent predictor of death/disability at the end of the $12^{\text {th }}$ month in patients with acute cerebral infarction. Thus, there were several reports that reduced CFR was associated with cardiovascular disease, and reduced eGFR was associated with cardio-cerebrovascular event, however, there was no report to reveal correlation with CFR and cerebrovascular events. In the present study, low CFR and/or CKD were associated with a high rate of long-term cardio-cerebrovascular events in the patients without obstructive coronary artery disease and vasospasm.

Microvascular dysfunction appears to be part of a systemic process ${ }^{33,34)}$. The functional capacity of the myocardial microcirculation may be assessed by CFR, and GFR may in part reflect and rely on the integrity of the renal microvascular bed. Impairment in both microcirculatory beds may reflect an unmeasured risk factor induced by blunted renal function and add a burden to the increased propensity for vascular events in $\mathrm{CKD}^{10)}$. Cerebrovascular events are also caused by the presence of microvascular dysfunction, and it is considered that similar histopathological changes in several vascular beds may occur nearly simultaneously ${ }^{35-38)}$. From our study, it has possibilities that the existence of low CFR and GFR reflects not only coronary and renal arterial microvascular dysfunction, but also systemic microvasculature such as cerebral infarction.

Limitations : Our study has several limitations. 1) It was performed in a single center and small scale including 73 patients, which may not represent the whole Japanese population. 2) CFR was measured only in the LAD. There is no doubt that the 3-coronary approach would be more fruitful, but it remains technically challenging. 3) Doppler assessment of CFR has some limitations. For example, assessment of absolute blood velocity can be limited in some patients by the large incident angle between the Doppler beam and blood flow.

\section{CONCLUSIONS}

In conclusion, our data suggest that coronary microvascular dysfunction is associated with CKD. The presence of both of low CFR and CKD may be important predictors for cardio-cerebrovascular events in the patients without coronary stenosis and vasospasm. 


\section{REFERENCES}

1. Kemp HG, Vokonas PS, Cohn PF, Gorlin R. The anginal syndrome associated with normal coronary arteriograms : report of six-year experience. Am J Med, 54 : 735-742, 1973.

2. Proudfit WL, Shirey EK, Sones FM Jr. Selective cinecoronary arteriography : correlation with clinical findings in 1,000 patients. Circulation, 33 : 901-910, 1966.

3. Marchandise B, Bourassa MG, Chaitman BR, Lesperance J. Angiographic evaluation of the natural history of normal coronary arteriograms and mild coronary atherosclerosis. Am J Cardiol, 41 : 216-220, 1978.

4. Sade LE, Eroglu S, Bozbaş H, Ozbiçer S, Hayran M, Haberal A, Müderrisoğlu H. Relation between epicardial fat thickness and coronary flow reserve in women with chest pain and angiographically normal coronary arteries. Atherosclerosis, 204 : 580-585, 2009.

5. Tonelli M, Moyé L, Sacks FM, Kiberd B, Curhan G; Cholesterol and Recurrent Events (CARE) Trial Investigators. Pravastatin for secondary prevention of cardiovascular events in persons with mild chronic renal insufficiency. Ann Int Med, 138 : 98-104, 2003.

6. Reis SE, Olson MB, Fried L, Reeser V, Mankad S, Pepine CJ, Kerensky R, Merz CN, Sharaf BL, Sopko G, Rogers WJ, Holubkov R. Mild renal insufficiency is associated with angiographic coronary artery disease in women. Circulation, 105 : 2826-2829, 2002.

7. Henry RM, Kostense PJ, Bos G, Dekker JM, Nijpels G, Heine RJ, Bouter LM, Stehouwer CD. Mild renal insufficiency is associated with increased cardiovascular mortality: the Hoorn Study. Kidney Int, 62 : 1402-1407, 2002.

8. Fried LF, Shlipak MG, Crump C, Bleyer AJ, Gottdiener JS, Kronmal RA, Kuller LH, Newman AB. Renal insufficiency as a predictor of cardiovascular outcomes and mortality in elderly individuals. J Am Coll Cardiol, 41 : 1364-1372, 2003.

9. Ovbiagele B. Impairment in glomerular filtration rate or glomerular filtration barrier and occurrence of stroke. Arch Neurol, 65 : 934-938, 2008.

10. Chade AR, Brosh D, Higano ST, Lennon RJ, Lerman LO, Lerman A. Mild renal insufficiency is associated with reduced coronary flow in patients with non-obstructive coronary artery disease. Kidney Int, 69 : 266-271, 2006.

11. Schwartzkopff B, Motz W, Frenzel H, Vogt M, Knauer S, Strauer BE. Structural and functional alterations of the intramyocardial coronary arterioles in patients with arterial hypertension. Circulation, 88 : 993-1003, 1993.
12 Opherk D, Mall G, Zebe H, Schwarz F, Weihe E, Manthey J, Kübler W. Reduction of coronary reserve: a mechanism for angina pectoris in patients with arterial hypertension and normal coronary arteries. Circulation, 69 : 1-7, 1984.

13. Brush JE Jr, Cannon RO 3rd, Schenke WH, Bonow RO, Leon MB, Maron BJ, Epstein SE. Angina due to coronary microvascular disease in hypertensive patients without left ventricular hypertrophy. N Engl J Med, 319 : 1302-1307, 1988.

14. Matsuo S, Imai E, Horio M, Yasuda Y, Tomita K, Nitta K, Yamagata K, Tomino Y, Yokoyama H, Hishida A. Revised equations for estimated GFR from serum creatinine in Japan. Am J Kidney Dis, 53 : 982-992, 2009.

15. Sarnak MJ, Levey AS, Schoolwerth AC, Coresh J, Culleton B, Hamm LL, Mc-Cullough PA, Kasiske BL, Kelepouris E, Klag MJ, Parfrey P, Pfeffer M, Raij L, Spinosa DJ, Wilson PW. Kidney disease as a risk factor for development of cardiovascular disease : a statement from the American Heart Association Councils on Kidney in Cardiovascular Disease, High Blood Pressure Research, Clinical Cardiology, and Epidemiology and Prevention. Circulation, 108 : 2154-2169, 2003.

16. JCS Joint Working Group. Guidelines for diagnosis and treatment of patients with vasospastic angina (coronary spastic angina) (JCS 2008) : digest version. Circ J, 74 : 1745-1762, 2010.

17. Yaoita H, Yamaki T, Mizugami H, Sakamoto N, Kawamura K, Ujiie Y, Maehara K, Maruyama Y. A case of recurrent chest pain with reversible left ventricular dysfunction and ST segment elevation on electrocardiogram. Int Heart J, 1 : 147-152, 2005.

18. Buus NH, Bøttcher M, Hermansen F, Sander M, Nielsen TT, Mulvany MJ. Influence of nitric oxide synthase and adrenergic inhibition on adenosine-induced myocardial hyperemia. Circulation, 104 : 2305-2310, 2001.

19. Leipert B, Becker BF, Gerlach E. Different endothelial mechanism involved in coronary responses to known vasodilators. Am J Physiol, 262 : H1676-1683, 1992.

20. Stam F, van Guldener C, Schalkwijk CG, ter Wee PM, Donker AJ, Stehouwer CD. Impaired renal function is associated with markers of endothelial dysfunction and increased inflammatory activity. Nephrol Dial Transplant, 18 : 892-898, 2003.

21. Hojs Fabjan T, Hojs R, Tetickovic E, Pecovnik Balon B. Ischemic stroke-impact of renal dysfunction on in-hospital mortality. Eur J Neurol, 14 : 1351-1356, 2007.

22. Yahalom G, Schwartz R, Schwammenthal Y, Merzeliak O, Toashi M, Orion D, Sela BA, Tanne D. Chronic kidney disease and clinical outcome 
in patients with acute stroke. Stroke, 40 : 12961303, 2009.

23. Friedman PJ. Serum creatinine : an independent predictor of survival after stroke. J Intern Med, 229 : 175-179, 1991.

24. Koivuviita N, Tertti R, Järvisalo $M$, Pietilä $M$, Hannukainen J, Sundell J, Nuutila P, Knuuti J, Metsärinne K. Increased basal myocardial perfusion in patients with chronic kidney disease without symptomatic coronary artery disease. Nephrol Dial Transplant, 24 : 2773-2779, 2009.

25. Bezante GP, Viazzi F, Leoncini G, Ratto E, Conti N, Balbi M, Agosti S, Deferrari L, Deferrari G, Pontremoli R. Coronary flow reserve is impaired in hypertensive patients with subclinical renal damage. Am J Hypertens, 22 : 191-196, 2009.

26. Charytan DM, Shelbert HR, Di Carli MF. Coronary microvascular function in early chronic kidney disease. Circ Cardiovasc Imaging, 3 : 663-671, 2010.

27. Koga S, Ikeda S, Nakata T, Yasunaga T, Takeno M, Koide Y, Maemura K. Low glomerular filtration rate is associated with high prevalence of vasospastic angina. Circ J, 75 : 1691-1695, 2011.

28. Mullins PA, Chauhan A, Sharples L, Cary NR, Large SR, Wallwork J, Schofield PM. Impairment of coronary flow reserve in orthotopic cardiac transplant recipients with minor coronary occlusive disease. Br Heart J, 68 : 266-271, 1992.

29. Levey AS, Beto JA, Coronado BE, Eknoyan G, Foley RN, Kasiske BL, Klag MJ, Mailloux LU, Manske CL, Meyer KB, Parfrey PS, Pfeffer MA, Wenger NK, Wilson PW, Wright JT Jr. Controlling the epidemic of cardiovascular disease in chronic renal disease: what do we know? What do we need to learn? Where do we go from here? National Kidney Foundation Task Force on Cardiovascular Disease. Am J Kidney Dis, 32 : 853-906, 1998.

30. Go AS, Chertow GM, Fan D, McCulloch CE, Hsu
CY. Chronic kidney disease and the risks of death, cardiovascular events, and hospitalization. N Engl J Med, 351 : 1296-1305, 2004.

31. Koren-Morag N, Goldbourt U, Tanne D. Renal dysfunction and risk of ischemic stroke or TIA in patients with cardiovascular disease. Neurology, 67 : 224-228, 2006.

32. Hao Z, Wu B, Lin S, Kong FY, Tao WD, Wang DR, Liu M. Association between renal function and clinical outcome in patients with acute stroke. Eur Neurol, 63 : 237-242, 2010.

33. Sax FL, Cannon RO 3rd, Hanson C, Epstein SE. Impaired forearm vasodilator reserve in patients with microvascular angina. Evidence of a generalized disorder of vascular function? N Engl J Med, 317 : 1366-1370, 1987.

34. Lekakis JP, Papamichael CM, Vemmos CN, Voutsas AA, Stamatelopoulos SF, Moulopoulos SD. Peripheral vascular endothelial dysfunction in patients with angina pectoris and normal coronary arteriograms. J Am Coll Cardiol, 31 : 541-546, 1998.

35. Imig JD, Inscho EW. Adaptations of the renal microcirculation to hypertension. Microcirculation, 9 : 315-328, 2002.

36. Burchfiel CM, Tracy RE, Chyou PH, Strong JP. Cardiovascular risk factors and hyalinization of renal arterioles at autopsy. The Honolulu Heart Program. Arterioscler Thromb Vasc Biol, 17 : 760-768, 1997.

37. Kaski JC. Myocardial ischemia in the hypertensive patient- the role of coronary microcirculation abnormalities. Eur Heart J, 14(Suppl J) : 32-37, 1993.

38. Kozàkovà M, Palombo C, Pratali L, Pittella G, Galetta F, L'Abbate A. Mechanisms of coronary flow reserve impairment in human hypertension. An integrated approach by transthoracic and transesophageal echocardiography. Hypertension, 29 : 551-559, 1997. 